\title{
A CORRELATION OF CLINICAL AND HEMODYNAMIC STUDIES IN PATIENTS WITH HYPOTHYROIDISM ${ }^{1}$
}

\author{
By JOHN S. GRAETTINGER, JOSEPH J. MUENSTER, ${ }^{2}$ CARLO S. CHECCHIA, ${ }^{3}$ \\ ROBERT L. GRISSOM,4 AND JAMES A. CAMPBELL
}

\author{
(From the Cardio-Respiratory Division, Department of Medicine, Presbyterian Hospital, and \\ Department of Medicine, University of Illinois College of Medicine, Chicago, Ill.)
}

(Submitted for publication July 16, 1957; accepted December 2, 1957)

Congestive heart failure has for many years been considered to be a possible complication of myxedema and, although heart disease of other etiologies has been described in patients with hypothyroidism, myxedematous involvement of the myocardium has sometimes been assumed to be a cause of congestive heart failure $(1-4)$. More commonly the term "myxedema heart" is used with the connotation of actual or potential myocardial malfunction associated with the myxedematous state (5-10). Postmortem studies have demonstrated that hydropic vacuolization of the myocardium may occasionally be found in the rare patient who succumbs with myxedema (11-14), but clinical data which support the concept of involvement of the heart to the extent of impairing cardiac function are not conclusive. Indeed, the improvement in cardiac decompensation which commonly occurs when a patient with severe heart failure is rendered hypothyroid is well documented $(15,16)$. Physiologic studies in patients with hypothyroidsm have established that the cardiac output is low and that the circulation time is often moderately prolonged. In the majority of patients studied the reduction in cardiac output has been found to be proportional to the decreased oxygen consumption with the arteriovenous difference normal; other investigators have noted a somewhat greater reduction in cardiac output than in oxygen consumption with a somewhat increased arteriovenous difference (17-29). Pressures within the heart and the pulmonary and systemic

\footnotetext{
1 This work was supported in part by a grant from the United States Public Health Service (USPHS H404), and in part by a grant from the Otho S. A. Sprague Memorial Institute.

2 This work was done during the tenure of a James B. Herrick Fellowship in Cardiology.

3 Present address: Cleveland Clinic, Cleveland, Ohio.

4. This work was done during the tenure of a John and Mary R. Markle Scholarship in Medical Science. Present address: Department of Medicine, University of Nebraska, Omaha, Nebraska.
}

circulations have been found to be within normal limits $(22,26)$. These data obtained in resting patients suggest that although the cardiac output is low in hypothyroidism it is adequate in the presence of decreased circulatory load. Since symptoms and hemodynamic abnormalities frequently occur only during exercise in patients with marginal cardiac compensation, the finding of normal values at rest in patients with hypothyroidism does not necessarily exclude impaired myocardial reserve. Normal circulatory responses to exercise were noted in two patients studied by Ellis, Mebane, Maresh, Hultgren, and Bloomfield (22). In the present paper we are reporting a correlation of the clinical syndrome of hypothyroidism with physiologic data obtained at rest and during exercise in twelve patients studied as part of an investigation of the relationship of various types of clinical heart disease and congestive failure to hemodynamic changes. These patients will be compared with healthy subjects and with patients who were in congestive heart failure from ultimately fatal myocardial disease (30).

\section{MATERIAL AND METHODS}

Twelve patients with hypothyroidism have been studied whose ages ranged from 17 to 59 years; 10 were over 40 and 4 over 50 . All had had symptoms of hypothyroidism for over one year. Dry skin and hair, puffiness of the face and other signs of myxedema were present in each at the time of study. Confirmatory laboratory data are shown in Table I. None had distended neck veins or persistent signs of pulmonary congestion, although transient rales were present at the lung bases in one patient (R. C.). Another patient (E. D.) had rheumatic heart disease with mitral insufficiency and stenosis with characteristic auscultatory and roentgenographic findings. Slight hepatomegaly was present in five patients, pitting edema of the legs in four, and ascites in one. Enlargement of the cardiac silhouette was evident in the teleroentgenograms of eight patients. The contour in three was regarded as diagnostic of pericardial effusion and of right and left ventricular and left atrial enlargement in the patient with rheumatic heart disease. Generalized enlargement without 
diagnostic configuration was noted in the films of the other four patients. Arm to tongue circulation time (Decholin ${ }^{\circledR}$ ) was normal in three (R. B., 17 seconds; V. B., 17 seconds; C. R., 15 seconds) and prolonged in three (L. L., 25 seconds; A. S., 24 seconds; R. C., 22 seconds) of the six patients in whom this determination was made; in one of the patients (L. L.) with prolonged circulation time, the heart was enlarged and a small pleural effusion was present. Total blood volumes were normal to low in the five patients in whom it was measured: E. C., -19 per cent; L. L., +7 per cent; C. R., -33 per cent; R. B., -17 per cent; E. L., -33 per cent. The electrocardiograms of each of these patients revealed normal sinus rhythm; one showed normal voltage of $Q R S-T$, five low voltage of the QRS-T deflections, and six low voltage of the $T$ waves. The electrocardiogram of E. D. with rheumatic heart disease also suggested right ventricular hypertrophy. Their hemoglobins ranged from 7.6 to $11.8 \mathrm{Gm}$.

Data obtained in seven patients with typical clinical congestive failure from ultimately fatal myocardial disease without evidence of valvular heart disease are compared with the data obtained in the patients with hypothyroidism. Postmortem examination disclosed nonspecific myocarditis in four patients, amyloid disease involving the myocardium in another, and myocardial atrophy following pericardial resection in another. No postmortem examination was obtained in the seventh patient who clinically was diagnosed as myocardial disease of unknown etiology.

The studies were performed in an air-conditioned room on patients in the postabsorptive state, usually after a sedative dose of sodium allyl barbiturate. Cardiac catheterization was performed in the usual manner after insertion of a Cournand needle into a brachial artery. Simultaneous venous blood samples from the pulmonary artery (nine patients) or right atrium (three patients) and arterial samples were collected anaerobically together with expired air samples in Douglas bags at rest and during the fourth minute of exercise on a stationary bicycle with the patient in the supine position. Arterial and venous oxygen contents and arterial oxygen capacity were determined by the method of Van Slyke and Neill (31). Oxygen and carbon dioxide concentrations in expired air were measured either by the microScholander technique (32) or by the use of a Pauling oxygen analyzer and Haldane manometric apparatus. Intravascular pressures were recorded from strain gauges placed $10 \mathrm{~cm}$. above the level of the patient's back, and mean pressures were obtained by planimetry. $\mathrm{I}^{131}$ was used for determination of blood volume. Body surface area was determined on the basis of height and weight at the time of study in all patients.

\section{RESULTS}

The hemodynamic data together with the hemoglobin and metabolic rate at the time of study and the serum cholesterol or $\mathrm{I}^{131}$ uptake of each patient are presented in Table I. The mean data and standard errors obtained in five healthy subjects are tabulated at the bottom of each column together with the probability of the observed differences between the hypothyroid patients and healthy subjects being attributable to chance.

\section{Cardiac output index}

The resting cardiac index of each patient was considerably below normal without apparent relationship to the hemoglobin level, heart size or presence or absence of pericardial effusion, and the difference of the mean of $1.88 \pm \mathrm{S}$. D. $0.8 \mathrm{~L}$. per minute per $\mathrm{M}^{2}{ }^{2}$ from the normal was highly significant. During exercise, an increase in cardiac output occurred in all patients; in two, E. D. with rheumatic heart disease and E. L. who clinically presented the most severe hypothyroidism in this group of patients, the increase was slight. The mean increase in output for the entire group to $3.05 \pm \mathrm{S}$. D. $0.77 \mathrm{~L}$. per minute per $\mathrm{M}^{2}$ ( +62 per cent) was highly significant and represents a greater proportional increase than has usually been observed in healthy persons performing the exercise test ( +51 per cent).

\section{Cardiac output:oxygen consumption ratio}

The ratio of cardiac output to oxygen consumption (the reciprocal of the arteriovenous difference) in the hypothyroid patients was not significantly different from normal either at rest or exercise although it was below the normal range for our laboratory of $2.32 \pm \mathrm{S}$. D. 0.13 in four patients. These relationships are plotted in Figure 1 together with the regression line of these data measured at rest. The cardiac output at rest in these patients with myxedema was directly related to the level of oxygen consumption ( $r=$ $0.71, p<0.01)$. The ratio of the increase in cardiac output to the increase in oxygen consumption during exercise appears in Table I and is represented by the slope of the lines connecting the rest and exercise data for each patient in the figure. With one exception, E. D. with mitral stenosis and insufficiency, this ratio was as great or greater than that usually found in healthy persons (33).

\section{Stroke volume index and heart rate}

The considerable decrease in basal cardiac output in these patients was primarily attributable to 
TABLE I

Hemodynamic data in patients with hypothyroidism compared with those of normal subjects

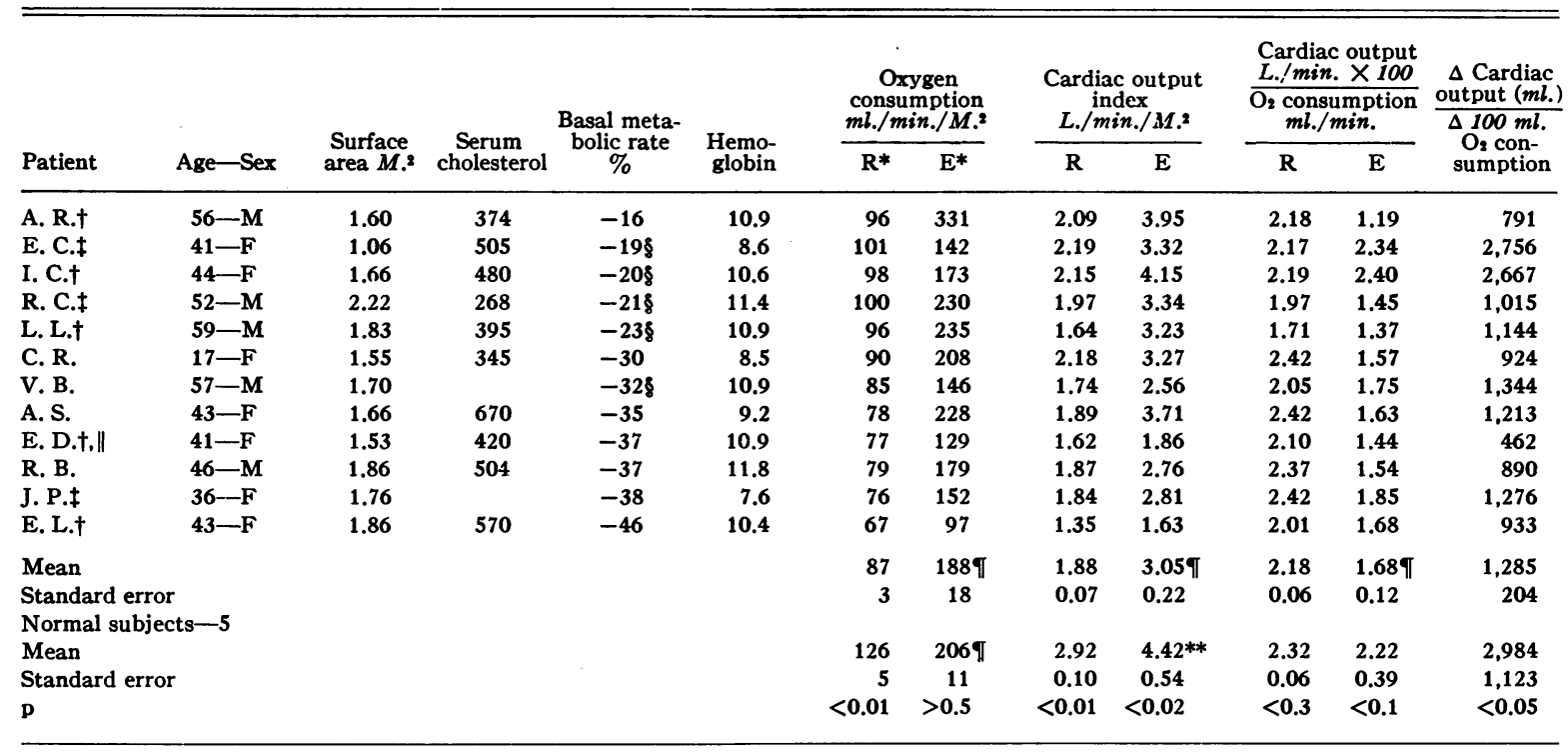

$* \mathbf{R}=$ Rest. $\quad \mathrm{E}=$ Exercise.

$\dagger$ Enlarged cardiac silhouette.

$\ddagger$ Pericardial effusion.

$\$$ I $^{121}$ uptake $<10$ per cent.

a significant decrease in stroke volume in the presence of a low normal heart rate. During exercise, the rise in output observed occurred in the majority of the patients primarily by an increase in stroke volume, but in two patients (C. R. and R. B.) the increase was primarily because of an increase in heart rate. The two patients who increased their cardiac outputs only slightly during exercise also failed to increase their pulse rates significantly. For the group, the increase in both heart rate and stroke volume index was significant.

\section{Arteriovenous oxygen difference}

The arteriovenous oxygen difference in 4 of the 12 patients was higher than the normal range in our laboratory $(4.33 \pm \mathrm{S}$. D. 0.24 volume per cent), but the mean value for the group, $4.66 \pm$ S. D. 0.52, although in the high normal range, did not differ significantly from the normal. During exercise, the mean arteriovenous difference increased to $6.15 \pm$ S. D. 0.19 which was not significantly higher than in healthy persons. The arteriovenous differences observed in the two patients who demonstrated only slight increases in cardiac output (E. D. and E. L.) did not differ from those of the other patients. The mean oxygen extraction ratios (arteriovenous difference divided by arterial oxygen content) of $36.7 \pm$ S. D. 4.4 per cent at rest and $46.9 \pm$ S. D. 7.2 per cent at exercise were not significantly higher than these observed in euthyroid patients with similar levels of anemia (30).

\section{Right atrial pressure}

The mean atrial pressures were slightly elevated at rest in five patients (A. R., I. C., R. C., E. D., and J. P.) but did not increase significantly with exercise. In two patients (I. C. and E. L.) atrial pressure rose slightly with exercise. In none of the patients with normal size of the cardiac silhouette was elevation of the atrial pressure at rest or exercise observed. The mean for the group did not differ significantly from the normal either at rest or during exercise.

\section{Right ventricular pressure}

Right ventricular pressure tracings were recorded in eight patients. Tracings were obtained in two of the four patients with normal sized cardiac silhouettes (A. S. and C. R.). The pressure dropped to zero after systole and rose to 5 $\mathrm{mm} . \mathrm{Hg}$ at the end of diastole. Pressure curves were recorded in each of the three patients with definite pericardial effusions and "diastolic dips" 
TABLE I-Continued

Hemodynamic data in patients with hypothyroidism compared with those of normal subjects

\begin{tabular}{|c|c|c|c|c|c|c|c|c|c|c|c|c|c|c|c|}
\hline \multicolumn{2}{|c|}{$\begin{array}{l}\text { Stroke volume } \\
\text { index } \\
\text { ml./beat/M.2 }\end{array}$} & \multicolumn{2}{|c|}{$\begin{array}{l}\text { Heart rate } \\
\text { beats/minute }\end{array}$} & \multicolumn{2}{|c|}{$\begin{array}{l}\text { A-V oxygen } \\
\text { difference } \\
m l . / 100 \mathrm{ml} .\end{array}$} & \multicolumn{2}{|c|}{$\begin{array}{c}\text { Right atrial } \\
\text { pressure } \\
\mathbf{m m} . \mathbf{H g}\end{array}$} & \multicolumn{2}{|c|}{$\begin{array}{l}\text { Mean pulmo- } \\
\text { nary artery } \\
\text { pressure } \\
\text { mm. } \mathbf{H g}\end{array}$} & \multicolumn{2}{|c|}{$\begin{array}{c}\text { Mean bra- } \\
\text { chial artery } \\
\text { pressure } \\
m m . H g\end{array}$} & \multicolumn{2}{|c|}{$\begin{array}{c}\text { Total pulmonary } \\
\text { resistance } \\
\text { dynes } \mathrm{cm} . \text { sec. } .^{-5}\end{array}$} & \multicolumn{2}{|c|}{$\begin{array}{l}\text { Total systemic } \\
\text { resistance } \\
\text { dynes } \mathrm{cm} . \mathrm{sec}^{-5}\end{array}$} \\
\hline $\mathbf{R}$ & $\mathrm{E}$ & $\mathbf{R}$ & $\mathbf{E}$ & $\mathbf{R}$ & $\mathrm{E}$ & $\mathbf{R}$ & $\mathrm{E}$ & $\mathbf{R}$ & $E$ & $\mathbf{R}$ & $\mathbf{E}$ & $\mathbf{R}$ & $\mathrm{E}$ & $\mathbf{R}$ & $\mathbf{E}$ \\
\hline 30 & 37 & 70 & 108 & 4.61 & 8.38 & 8 & 10 & 15 & 30 & 108 & 119 & 359 & 379 & 2,584 & 1,505 \\
\hline 28 & 36 & 79 & 93 & 4.58 & 4.28 & 5 & & 18 & 22 & 120 & 120 & 617 & 755 & 4,116 & 2,724 \\
\hline 30 & 53 & 72 & 79 & 4.58 & 4.17 & 11 & 14 & 23 & 26 & 106 & 120 & 515 & 302 & 2,372 & 1,395 \\
\hline 38 & 48 & 52 & 70 & 5.09 & 6.90 & 13 & 13 & 22 & 23 & 70 & 76 & 401 & 248 & 1,700 & 1,342 \\
\hline 28 & 45 & 57 & 70 & 5.90 & 7.28 & 5 & 7 & & & 105 & 117 & & & 2,815 & 1,582 \\
\hline 32 & 33 & 68 & 99 & 4.11 & 6.39 & 2 & 3 & 7 & 10 & 94 & 102 & 166 & 158 & 2,222 & 1,607 \\
\hline 37 & 51 & 47 & 50 & 4.88 & 5.71 & 1 & & 8 & 13 & 92 & 104 & 225 & 238 & 2,492 & 1,906 \\
\hline 26 & 44 & 74 & 85 & 4.16 & 6.13 & & 2 & 8 & 11 & 102 & 100 & 204 & 143 & 2,604 & 1,297 \\
\hline 26 & 31 & 62 & 60 & 4.75 & 6.83 & 7 & 7 & 20 & 26 & 71 & 75 & 645 & 732 & 2,288 & 2,110 \\
\hline 37 & 36 & 51 & 76 & 4.21 & 6.43 & 2 & 3 & & & 100 & 117 & & & 2,290 & 1,822 \\
\hline 28 & 36 & 65 & 79 & 4.10 & 5.42 & 10 & 6 & \multicolumn{2}{|c|}{$30 / 6 t t$} & 84 & 84 & & & 2,072 & 1,239 \\
\hline 19 & 22 & 71 & 73 & 4.95 & 5.94 & 5 & 9 & 18 & 23 & 106 & 103 & 573 & 603 & 3,375 & 2,698 \\
\hline 30 & $39 \llbracket$ & 64 & 799 & 4.66 & 6.15ף & 6 & 7 & 15 & 20ণা & 97 & $103 \pi$ & 412 & 395 & 2,577 & $1,733 q$ \\
\hline 0.5 & 0.5 & 3 & 5 & 0.15 & 0.34 & 1 & 1 & 2 & 2 & 4 & 5 & 62 & 80 & 183 & 160 \\
\hline 41 & 51 & 72 & $86^{* *}$ & 4.33 & 5.01 & 3 & 3 & 15 & $20 * *$ & 94 & 99 & 260 & 258 & 1,558 & 1,124 \\
\hline 2 & 6 & 3 & 3 & 0.11 & 0.76 & 0.5 & 1 & 2 & 3 & 7 & 3 & 49 & 50 & 161 & 125 \\
\hline$<0.01$ & $<0.1$ & $<0.2$ & $<0.4$ & $<0.2$ & $<0.2$ & $<0.3$ & $<0.1$ & $>0.5$ & $>0.5$ & $>0.5$ & $>0.5$ & $<0.2$ & $<0.4$ & $<0.01$ & $<0.05$ \\
\hline
\end{tabular}

\| Rheumatic heart disease.

II Significant change with exercise, $\mathrm{p}<0.01$.

** Significant change with exercise, $p<0.05$.

\# Right ventricular pressure.

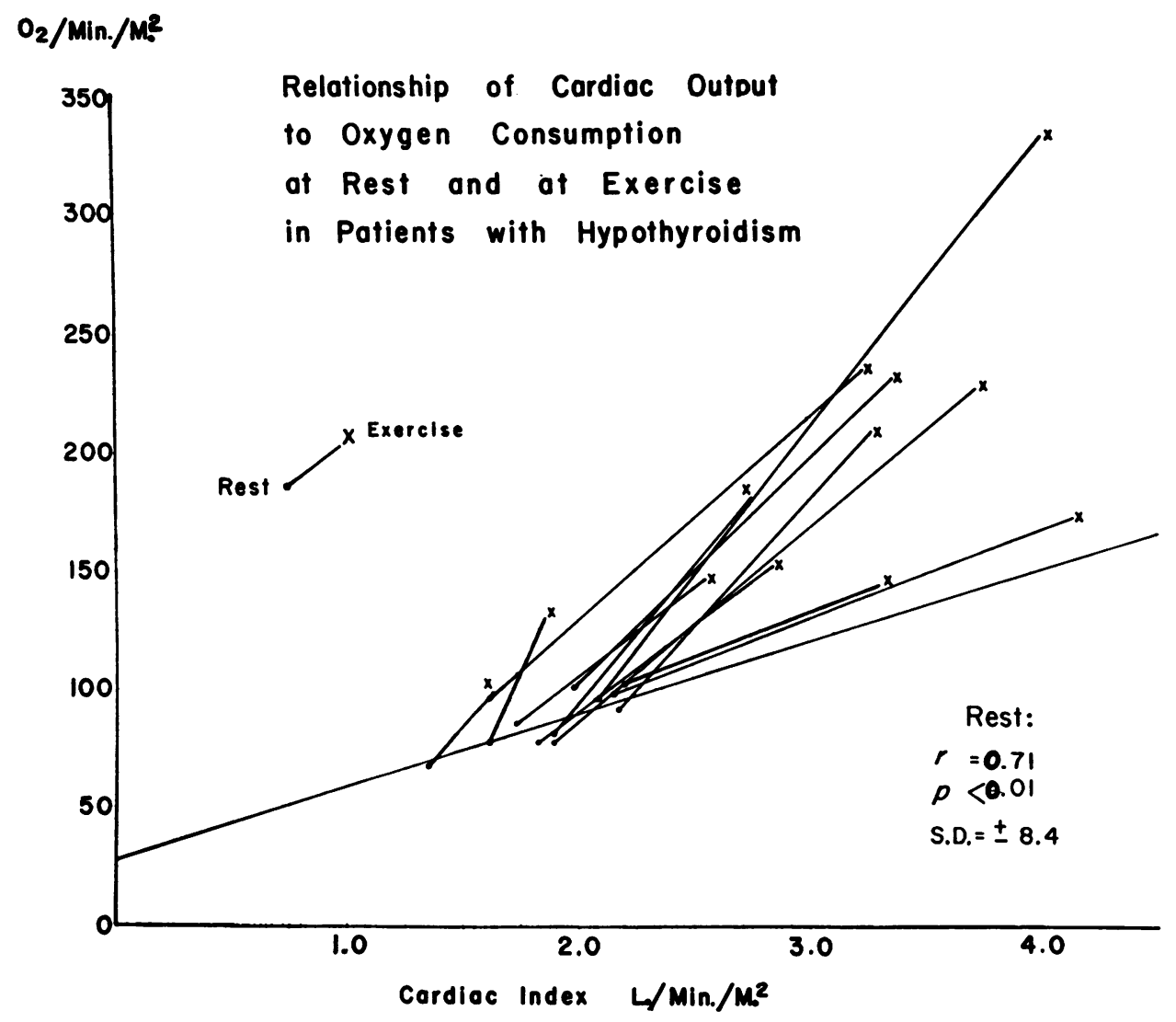

Fig. 1. Relationship of Cardiac Output to Oxygen Consumption at Rest and at Exercise in Patients with Hypothyroidism 
were present (E. C., 22/2/8; R. C., 30/5/13; J. P., 30/-2/6). Ventricular pressure tracings were obtained in only three of the five other patients with enlarged cardiac silhouettes but without evident 'effusions; in two (A. R. and E. L.) a moderate "diastolic dip" was present $(31 / 5 / 10$ and $28 / 4 / 8$ ) ; in the third, E. D. with rheumatic heart disease, the contour was similar $(38 / 1 / 8)$. These tracings suggest the possibility that pericardial effusion with restriction of diastolic filling may have been present in these three patients with nondiagnostic enlargement of the cardiac silhouette as well as in the three patients with presumptive radiographic evidence of effusion.

\section{Pulmonary artery pressure}

In the nine patients in whom measurements were obtained, the mean pulmonary arterial pressures were normal at rest; the mean pressure was under $10 \mathrm{~mm} . \mathrm{Hg}$ in three patients with normal size of the cardiac silhouette and $15 \mathrm{~mm}$. to $23 \mathrm{~mm}$. in six patients with enlarged cardiac silhouettes. During exercise the mean pulmonary pressure rose to less than $15 \mathrm{~mm}$. Hg in the first three patients; in three of the patients with enlarged heart shadows (A. R., I. C., and E. D.) slight pulmonary hypertension developed, and in the other three patients with enlarged cardiac silhouettes, including two with pericardial effusion (E. C., R. C., and E. L.) the pulmonary pressure rose to upper normal limits. The means for the group did not differ significantly from the normal either at rest or during exercise.

\section{Systemic arterial pressure}

The mean brachial arterial pressures at rest in these patients were normal to high with definite hypertension present in one (E. C.). The mean for the group did not differ significantly from the normal. During exercise the systolic pressure rose in all patients who increased their cardiac outputs significantly and diastolic pressures rose in six, fell in two, and did not change in the two without significant increase in output. The slight increase in mean pressure for the group was significant.

\section{Total pulmonary resistance}

The calculated total pulmonary resistance was normal in the patients with normal heart size and increased in the patients with enlarged heart contours. Again the group mean did not differ significantly from normal. There was either no change or a decrease in pulmonary resistance during exercise in all patients.

\section{Total systemic resistance}

For the group, a significant increase in calculated total systemic resistance over the normal was found at rest and at exercise. A significant decrease in resistance occurred with exercise.

\section{DISCUSSION}

Our primary interest in studying patients with hypothyroidism was to assess the circulatory dynamics in a disorder in which some of the symptoms and signs have been ascribed to congestive heart failure and in which the cardiac output is known to be at levels commonly associated with congestive failure. Observations concerning some of the physiologic changes accompanying hypometabolism have been presented and compared with normal. The present discussion will concern a comparison of the clinical and hemodynamic data in the patients with hypothyroidism with those observed in patients with typical congestive heart failure from ultimately fatal myocardial disease.

Clinically each of our patients with marked hypothyroidism presented the picture of myxedema. In several instances moderate pitting of the lower extremities was present in addition to the typical brawny edema. In contrast to patients with congestive failure, however, the edema was not progressively more severe, was not notably related to posture and always included the periorbital region. Nocturia associated with amelioration or disappearance of edema so frequent in the edematous cardiac was not noted in these patients. Although exertional breathlessness was a frequent complaint, this was not relentlessly progressive and commonly was overshadowed by exertional fatigue. In sharp contrast to most of the patients with congestive failure, orthopnea did not occur in these patients.

Enlargement of the cardiac silhouette was present on examination in two-thirds of the patients. Roentgenographic examination disclosed presumptive evidence of pericardial effusion in three of 
TABLE II

Comparison of hemodynamic data in patients with hypothyroidism with those of patients in congestive heart failure*

\begin{tabular}{|c|c|c|c|c|c|c|}
\hline & \multicolumn{2}{|c|}{$\begin{array}{c}\text { Hypothyroid- } \\
12 \text { patients }\end{array}$} & \multicolumn{2}{|c|}{$\begin{array}{c}\text { Heart disease with failure- } \\
7 \text { patients } \\
\end{array}$} & \multicolumn{2}{|c|}{$\mathrm{p}$} \\
\hline & Rest & Exercise & Rest & Exercise & Rest & Exercise \\
\hline $\begin{array}{l}\text { Oxygen consumption } \\
\left(\mathrm{ml} . / \mathrm{min} . / M_{.}{ }^{2}\right)\end{array}$ & $87 \pm 3$ & $188 \pm 18 \dagger$ & $138 \pm 9$ & $202 \pm 17 \dagger$ & $<0.01$ & $>0.5$ \\
\hline $\begin{array}{l}\text { Cardiac output index } \\
(\text { L./min./M.2 })\end{array}$ & $1.88 \pm 0.07$ & $3.05 \pm 0.22 \dagger$ & $1.93 \pm 0.12$ & $2.11 \pm 0.20$ & $>0.5$ & $<0.02$ \\
\hline$\frac{\text { Cardiac output }(\mathrm{L} . / \mathrm{min} . \times 100)}{\text { Oxygen consumption }(\mathrm{ml} . / \mathrm{min} .)}$ & $2.18 \pm 0.06$ & $1.68 \pm 0.12 \dagger$ & $1.42 \pm 0.08$ & $1.04 \pm 0.05 \dagger$ & $<0.01$ & $<0.05$ \\
\hline$\frac{\Delta \text { Cardiac index }(m l .)}{\Delta(100 \text { ml. }) \text { oxygen consumption }}$ & \multicolumn{2}{|c|}{$+1,285 \pm 204$} & \multicolumn{2}{|c|}{$+304 \pm 214$} & \multicolumn{2}{|c|}{$<0.01$} \\
\hline $\begin{array}{l}\text { Stroke volume index } \\
\quad\left(\text { ml. } / \text { beat } / M .{ }^{2}\right)\end{array}$ & $30 \pm 0.5$ & $39 \pm 0.5 \dagger$ & $19 \pm 1$ & $17 \pm 1$ & $<0.01$ & $<0.01$ \\
\hline $\begin{array}{l}\text { Heart rate } \\
\quad(\text { beats } / \text { minute })\end{array}$ & $64 \pm 3$ & $79 \pm 5 \dagger$ & $103 \pm 5$ & $122 \pm 4 \dagger$ & $<0.01$ & $<0.01$ \\
\hline $\begin{array}{l}\text { A-V oxygen difference } \\
(\mathrm{ml} . / 100 \mathrm{ml} .)\end{array}$ & $4.66 \pm 0.15$ & $6.15 \pm 0.34 \dagger$ & $7.18 \pm 0.42$ & $9.83 \pm 0.51 \dagger$ & $<0.01$ & $<0.01$ \\
\hline $\begin{array}{l}\text { Right atrial pressure } \\
(\mathrm{mm} . \mathrm{Hg})\end{array}$ & $6 \pm 1$ & $7 \pm 1$ & $10 \pm 3$ & $21 \pm 3 \dagger$ & $<0.2$ & $<0.01$ \\
\hline $\begin{array}{l}\text { Mean pulmonary artery pressure } \\
\quad(m m . H g)\end{array}$ & $15 \pm 2$ & $20 \pm 2 \dagger$ & & & & \\
\hline $\begin{array}{l}\text { Mean brachial artery pressure } \\
\quad(m m . H g)\end{array}$ & $97 \pm 4$ & $103 \pm 5 \dagger$ & $100 \pm 7$ & $110 \pm 8$ & $>0.5$ & $<0.5$ \\
\hline $\begin{array}{l}\text { Total pulmonary resistance } \\
\left(\text { dynes } \mathrm{cm} . \mathrm{sec} .^{-5}\right)\end{array}$ & $412 \pm 62$ & $395 \pm 80$ & & & & \\
\hline $\begin{array}{l}\text { Total systemic resistance } \\
\left(\text { dynes } \mathrm{cm} . \mathrm{sec}^{-5}\right)\end{array}$ & $2,577 \pm 183$ & $1,733 \pm 160 \dagger$ & $2,345 \pm 204$ & $2,518 \pm 368$ & $<0.5$ & $<0.05$ \\
\hline
\end{tabular}

* Data are presented as means and standard errors.

$\dagger$ Significant change during exercise $(p<0.01)$.

these eight patients and right ventricular pressure contours, although obtained in only three of the other five, suggested the possibility of some limitation of diastolic filling. These data are consonant with the suggestion that the cardiac enlargement so common in hypothyroidism is frequently due to pericardial effusion (34-39) and is not a sign of cardiac dilatation.

The arm to tongue circulation times in these patients were in the upper normal to slightly prolonged range (15 to 25 seconds) and blood volumes were normal to low in the five patients in whom this determination was made. These observations are consonant with the numerous data contained in other reports of patients with hypothyroidism $(19,40-42)$ and differ from the considerably prolonged circulation times and increased blood volumes commonly found in patients with chronic congestive heart failure (43, 44). On the basis of the clinical evaluation of these patients it was felt, therefore, that in no in- stance could a definitive diagnosis of congestive heart failure be made.

The physiologic data obtained in these patients with myxedema differ in significant detail from those obtained in the patients with chronic congestive failure on the basis of myocardial disease as shown in Table II. At rest their cardiac outputs, although reduced to the level commonly found in the patients with "low output" congestive failure, were linearly related to the decreased oxygen consumption. The ratio of cardiac ouput to oxygen consumption did not differ from the healthy subjects. In the patients with myocardial disease and congestive failure the oxygen consumptions at rest and the basal metabolic rates were normal to somewhat elevated and hence the cardiac output was significantly lower with respect to the level of oxygen consumption than in either the patients with myxedema or healthy persons. This is reflected in the significantly higher arteriovenous difference and ratio of car- 
diac output to oxygen consumption. Their stroke volumes were markedly reduced and heart rates were elevated in contrast to the patients with myxedema.

The response of the cardiac output to exercise observed in these patients with hypothyroidism was first of all qualitatively the same as that observed in healthy persons. Furthermore, although the increase in oxygen consumption during exercise was greater than usually noted in healthy persons under similar conditions, the ratio of increase in cardiac output to increase in oxygen consumption (Table I) was considerably greater than the minimum of approximately 650 $\mathrm{ml}$. generally considered to be the normal response (33). Although the arteriovenous differences observed during exercise were higher than usually observed in healthy persons, the differences were not significant nor were the ratios of cardiac output to oxygen consumption during exercise different from those observed in the normal subjects. By contrast, in the patients with myocardial disease and congestive failure, the cardiac output either did not increase significantly or actually decreased during exercise. Any increase was due to tachycardia since stroke volume index remained unchanged. Since oxygen consumption showed the expected increase the arteriovenous differences became even more abnormal. The arteriovenous difference during exercise was greater in every patient in failure than the maximum value of 8.38 volumes per cent (A. R.) noted in the patients with hypothyroidism.

The reduced cardiac output in the patients with hypothyroidism was associated with normal to slightly elevated pressures in the right atrium, pulmonary artery, and brachial artery and with considerably increased calculated total systemic resistance. During exercise, despite a significant increase in both brachial and pulmonary arterial pressure, a marked drop in calculated systemic resistance and no change in pulmonary resistance occurred, as is usually observed in normal persons. In the patients with congestive failure, on the other hand, the elevated atrial pressures became significantly more abnormal despite the failure of cardiac output to increase, and calculated systemic resistance did not decrease. Pulmonary arterial pressures and calculated total pulmonary resistances in patients with congestive failure are high at rest and become more abnormal during exercise (45-47). It is suggested that in hypometabolism the somewhat higher than expected right atrial, right ventricular end diastolic and pulmonary arterial mean pressures, and the presence of diastolic dips on the right ventricular pressure tracings found in patients with enlarged cardiac silhouettes may well reflect the effects of pericardial effusion and not the presence of myocardial failure.

Patient E. D., a 41 year old woman, is of particular importance. She had rheumatic heart disease with the physical findings of mitral insufficiency and stenosis. She had been in typical congestive heart failure three years prior to study and required digitalis and diuretic therapy. One and a half years prior to study she had discontinued medication without return of symptoms. At about this time myxedema became evident clinically. On examination, despite the evidence of rheumatic heart disease with left and right ventricular and left atrial enlargement confirmed at fluoroscopy, she presented no evidence of congestive failure. Her physiologic studies at rest did not differ from the other patients. During exercise, however, her cardiac output rose only $462 \mathrm{ml}$. per $100 \mathrm{ml}$. increase in oxygen consumption, a value lower than in any other patient. This finding, which is suggestive of a decreased myocardial reserve, together with the history and other clinical data, suggests that her myocardial reserve was perhaps adequate for the reduced metabolic load of hypothyroidism but had not been adequate for that of her previous euthyroid state.

The hemodynamic data obtained in these twelve patients with hypothyroidism corroborate the clinical decision that congestive heart failure was not present and strongly suggest that, with the possible exception of the patient with overt rheumatic heart disease, no significant myocardial impairment was present.

A review of other clinical $(1-4,6,10)$ and physiologic (22) studies made in patients reputed to have congestive failure attributed to myxedema has not revealed data which differ importantly from those obtained in our 12 patients. Furthermore, other data have been obtained in patients with myxedema which suggest that the circulation is competent. Although glomerular filtration rate and renal plasma flow are reduced as they are 
in patients with chronic congestive failure, Davies, MacKinnon, and Platts (21) found that while a diet containing $10 \mathrm{Gm}$. of salt per day caused a rapid increase in weight and venous pressure in patients with congestive failure, a similar salt load was handled normally by patients with myxedema. In the light of these data it would appear that the physiologic protection afforded by the decreased circulatory demands of the hypothyroid state in our patients overshadowed in significance any morphologic changes in the myocardium associated with their myxedema.

\section{SUMMARY}

1. Clinical and hemodynamic studies made in 12 patients with myxedema have been compared with those obtained in 7 euthyroid patients with chronic congestive failure from primary myocardial disease.

2. In the hypothyroid patients the low cardiac outputs increased and the elevated systemic resistances decreased normally with exercise in contrast to the patients with congestive failure.

3. The mean arteriovenous oxygen difference in the patients with myxedema was not significantly different from that found in the healthy subjects at rest or during exercise. In the patients with congestive heart failure, abnormally widened arteriovenous differences became yet more abnormal during exercise.

4. In view of the normal responses of cardiac output and arteriovenous differences to exercise in the patients with myxedema, the finding of slightly elevated mean pressures in the right atria and pulmonary arteries, end diastolic right ventricular pressures, and diastolic dips in the right ventricular pressure curves in the patients with myxedema with enlarged cardiac silhouettes suggested the possibility of pericardial effusion rather than cardiac dilatation as a cause of the enlarged cardiac contour.

\section{REFERENCES}

1. Zondek, H. Das Myxödemherz. Münch. med. Wschr. 1918, 65, 1180.

2. Assmann, H. Das Myxödemherz. Münch. med. Wschr. 1919, 66, 9.

3. Fahr, G. Myxedema heart. J. Amer. med. Ass. 1925, 84, 345.
4. Hallock, P. The heart in myxedema, with a report of 2 cases. Amer. Heart J. 1933, 9, 196.

5. Fishberg, A. M. Heart Failure, 2nd ed. Philadelphia, Lea and Febiger, 1940, p. 590.

6. McGavack, T. H., Lange, K., and Schwimmer, D. Management of the myxedematous patient with symptoms of cardiovascular disease. Amer. Heart J. 1945, 29, 421.

7. Reich, N. E. The Uncommon Heart Diseases. Springfield, Charles C Thomas, 1954, p. 293.

8. White, P. D. Heart Disease, 3rd ed. New York, The Macmillan Company, 1944, p. 453.

9. Yater, W. M. Fundamentals of internal medicine, 4th ed. New York, Appleton-Century-Crofts, Inc., 1954 , p. 40.

10. Ohler, W. R., and Abramson, J. Heart in myxedema. Arch. intern. Med. 1934, 53, 165.

11. Foster, M., and Barr, D. Myxedema: Record of autopsied case with special emphasis upon lesions of muscles. J. clin. Endocr. 1944, 4, 417.

12. Gould, S. E. Pathology of the Heart. Springfield, Charles C Thomas, 1953, p. 525.

13. Ladue, J. S. Myxedema heart: A pathologic and therapeutic study. Ann. intern. Med. 1943, 18, 332.

14. Webster, B., and Cooke, C. Morphologic changes in the heart in experimental myxedema. Arch. intern. Med. 1936, 58, 269.

15. Blumgart, H. L., Levine, S. A., and Berlin, D. D. Congestive heart failure and angina pectoris: Therapeutic effect of thyroidectomy on patients without clinical or pathologic evidence of thyroid toxicity. Arch. intern. Med. 1933, 51, 866.

16. Blumgart, H. L., and Freedberg, A. S. Heart and the thyroid: With particular reference to $I^{131}$ treatment of heart disease. Circulation 1952, 6, 222.

17. Altschule, M. D., and Volk, M. C. The minute volume output and the work of the heart in hypothyroidism. J. clin. Invest. 1935, 14, 385.

18. Altschule, M. D., and Volk, M. C. Therapeutic effect of total ablation of normal thyroid on congestive failure and angina pectoris. XVIII. The cardiac output following total thyroidectomy in patients with and without congestive heart failure, with a comparison of results obtained with acetylene and ethyl iodide methods. Arch. intern. Med. 1936, 58, 32.

19. Blumgart, H. L., Gargill, S. L., and Gilligan, D. R. Studies on the velocity of blood flow. XIV. The circulation in myxedema with a comparison of the velocity of blood flow in myxedema and thyrotoxicosis. J. clin. Invest. 1930, 9, 91.

20. Briard, S. P., McClintock, J. T., and Baldridge, C. W. Cost of work in patients with hypermetabolism due to leukemia and to exophthalmic goiter. Arch. intern. Med. 1935, 56, 30.

21. Davies, C. E., MacKinnon, J., and Platts, M. M. Renal circulation and cardiac output in "low output" heart failure and in myxoedema. Brit. med. J. 1952, 2, 595. 
22. Ellis, L. B., Mebane, J. G., Maresh, G., Hultgren, H. N., and Bloomfield, R. A. Effect of myxedema on the cardiovascular system. Amer. Heart J. 1952, 43, 341.

23. Higgins, W. H. Incipient hypothyroidism. J. Amer. med. Ass. 1925, 85, 1015.

24. Macy, J. W., Claiborne, T. S., and Hurxthal, L. M. The circulation rate in relation to metabolism in thyroid and pituitary states (Decholin method). J. clin. Invest. 1936, 15, 37.

25. Robinson, G. C. Measurement of the cardiac output in man and its variations. J. Amer. med. Ass. 1926, 87, 314.

26. Scheinberg, P., Stead, E. A., Jr., Brannon, E. S., and Warren, J. T. Correlative observations on cerebral metabolism and cardiac output in myxedema. J. clin. Invest. 1950, 29, 1139.

27. Starr, I., Jr., Collins, L. H., Jr., and Wood, F. C. Studies of the basal work and output of the heart in clinical conditions. J. clin. Invest. 1933, 12, 13.

28. Stewart, H. J., Deitrick, J. E., and Crane, N. F. Studies of the circulation in patients suffering from spontaneous myxedema. J. clin. Invest. 1938, 17, 237.

29. Stewart, H. J., and Evans, W. F. The peripheral blood flow in myxedema. Trans. Ass. Amer. Phycns 1941, 56, 233.

30. Graettinger, J. S., and Campbell, J. A. Unpublished data.

31. Van Slyke, D. D., and Neill, J. M. The determination of gases in blood and other solutions by vacuum extraction and manometric measurement. I. J. biol. Chem. 1924, 61, 523.

32. Scholander, P. F. Analyzer for accurate estimation of respiratory gases in one-half cubic centimeter samples. J. biol. Chem. 1947, 167, 235.

33. Ferrer, M. I., Harvey, R. M., Cathcart, R. T., Cournand, A., and Richards, D. W., Jr. Hemodynamic studies in rheumatic heart disease. Circulation 1952, 6, 688.

34. Gordon, A. H. Pericardial effusion in myxedema. Trans. Ass. Amer. Phycns 1935, 50, 272.

35. Kern, R. A., Soloff, L. A., Snape, W. J., and Bello, C. T. Pericardial effusion: A constant, early and major factor in the cardiac syndrome of hypothyroidism. Amer. J. med. Sci. 1949, 217, 609.

36. Lerman, J., Clark, R. J., and Means, J. H. Heart in myxedema. Ann. intern. Med. 1933, 6, 1251.

37. Schmidt, S. Pericardial effusion in myxoedema. Brit. J. Radiol. 1952, 25, 389.

38. Schnitzer, R., and Gutmann, D. Myxoedema with pericardial effusion. Brit. Heart J. 1946, 8, 25.

39. Marzullo, E. R., and Franco, S. Myxedema with multiple serous effusions and cardiac involvement. Amer. Heart J. 1939, 17, 368.

40. Aikawa, J. K. Nature of myxedema: Alterations in the serum electrolyte concentrations and radiosodium space and in the exchangeable sodium and potassium contents. Ann. intern. Med. 1956, 44, 30.

41. Gibson, J. G., 2d, and Harris, A. W. Clinical studies of the blood volume. V. Hyperthyroidism and myxedema. J. clin. Invest. 1939, 18, 59.

42. Thompson, W. O. Studies in blood volume. The blood volume in myxedema, with a comparison of plasma volume changes in myxedema and cardiac edema. J. clin. Invest. 1926, 2, 477.

43. Gibson, J. G., 2d, and Evans, W. A., Jr. Clinical studies of the blood volume. III. Changes in blood volume, venous pressure and blood velocity rate in chronic congestive heart failure. J. clin. Invest. 1937, 16, 851.

44. Gunton, R. W., and Paul, W. Blood volume in congestive heart failure. J. clin. Invest. 1955, 34, 879.

45. Hickam, J. B., and Cargill, W. H. Effect of exercise on cardiac output and pulmonary arterial pressure in normal persons and in patients with cardiovascular disease and pulmonary emphysema. J. clin. Invest. 1948, 27, 10.

46. Cournand, A. Some aspects of the pulmonary circulation in normal man and in chronic cardiopulmonary diseases. Circulation 1950, 2, 641.

47. Judson, W. E., Hollander, W., Hatcher, J. D., and Halperin, M. H. The effects of exercise on cardiovascular and renal function in cardiac pations with and without heart failure. J. clin. Invest. $1955,34,1546$.

\section{SPECIAL NOTICE TO SUBSCRIBERS}

Post Offices will no longer forward the Journal when you nove. Please notify. The Journal of Clinical Investigation, Business Office, 333 Cedar Street, New Haven 11, Conn., at once when you have a change of address, and do not omit the zone number if there is one. 